\title{
A constrained acetabular component for recurrent dislocation
}
R. J. K. Khan, D. Fick, R. Alakeson, S. Haebich, M. de Cruz, B. Nivbrant, D. Wood

\section{From Sir Charles} Gairdner Hospital, Perth, Western Australia
R. J. K. Khan, FRCS (Trauma \& Orth), Senior Lecturer R. Alakeson, FRCS, Lecturer in Orthopaedics

B. Nivbrant, PhD, Professor of Orthopaedics

D. Wood, MD, Professor of Orthopaedics

University of Western Australia, Nedlands, Perth 6009, Western Australia.

D. Fick, MBBS, Orthopaedic Registrar

M. de Cruz, MBBS,

Orthopaedic Registrar

Perth Orthopaedic Institute, Hollywood Private Hospital,

Nedlands, Perth 6009, Western

Australia.

S. Haebich, BSc, Senior Physiotherapist

Sir Charles Gairdner Hospital, Nedlands, Perth 6009, Western Australia.

Correspondence should be sent to Mr R. J. K. Khan at 1/14-16 Hamersley Street, Cottesloe, Western Australia 6011,

Australia; e-mail:

rjkkhan@gmail.com

(c)2006 British Editorial Society of Bone and Joint Surgery doi:10.1302/0301-620X.88B7. $17644 \$ 2.00$

$J$ Bone Joint Surg $[\mathrm{Br}]$ 2006;88-B:870-6.

Received 16 January 2006, Accepted after revision 16 March 2006

We treated 34 patients with recurrent dislocation of the hip with a constrained acetabular component. Roentgen stereophotogrammetric analysis was performed to assess migration of the prosthesis.

The mean clinical follow-up was 3.0 years $(2.2$ to 4.8$)$ and the radiological follow-up was 2.7 years $(2.0$ to 4.8$)$. At the latest review six patients had died and none was lost to followup. There were four acetabular revisions, three for aseptic loosening and one for deep infection. Another acetabular component was radiologically loose with progressive radiolucent lines in all Gruen zones and was awaiting revision. The overall rate of aseptic loosening was $11.8 \%$ (4 of 34). Roentgen stereophotogrammetric analysis in the nonrevised components confirmed migration of up to $1.06 \mathrm{~mm}$ of translation and $2.32^{\circ}$ of rotation at $\mathbf{2 4}$ months. There was one case of dislocation and dissociation of the component in the same patient. Of the 34 patients, $33(97.1 \%)$ had no further episodes of dislocation.

The constrained acetabular component reported in our study was effective in all but one patient with instability of the hip, but the rate of aseptic loosening was higher than has been reported previously and requires further investigation.

The prevalence of dislocation after primary total hip replacement (THR) is approximately $3 \%^{1}$ and rises to between $5 \%^{1,2}$ and $20 \%{ }^{3,4}$ for revision THR. The financial and functional costs are frequently underestimated. ${ }^{5,6}$ Predisposing factors include gluteal deficiency, trochanteric nonunion, soft-tissue imbalance, malposition of the components, impingement and neuromuscular disorders. ${ }^{7,8}$

Numerous surgical techniques have been described for the treatment of hip instability. These include correction of a malpositioned component, ${ }^{9,10}$ the use of a liner augmentation wedge $^{11,12}$ or angle-bore component, ${ }^{13}$ increase in the size of the femoral head with a jumbo head ${ }^{14-16}$ or bipolar hemiarthroplasty, ${ }^{17}$ removal of impinging tissue ${ }^{18}$ and bony or softtissue reconstruction. ${ }^{19-22}$ These have met with limited success. ${ }^{23}$

First described for the treatment of tuberculosis of the hip in the $1960 \mathrm{~s},{ }^{24}$ the constrained acetabular component has since been developed to manage instability when other methods have failed. It is designed to hold the head captive within the acetabular component by means of a locking mechanism. Forces which would otherwise cause dislocation are transferred to the locking mechanism and the liner- shell and shell-bone interfaces. The device is simple to use and provides immediate stability which has been reflected in the success reported in several large series. ${ }^{25-28}$ Potential disadvantages to the constrained liner include increased interfacial stresses resulting in acetabular loosening, dissociation of the constrained component requiring open reduction and reduced range of movement. . $^{25,29,30}$

Although often highlighted, the concerns about loosening of the component have not been thoroughly examined. Our aim in this prospective study was to report our clinical and radiological findings in a series of patients treated with the constrained component for recurrent dislocation, with emphasis on loosening of the implant using roentgen stereophotogrammetric analysis (RSA) in order to study migration of the prosthesis.

\section{Patients and Methods}

Ethical approval for the insertion of tantalum beads, (for RSA) was granted by the local human research ethics committee. The inclusion criterion for our study was recurrent dislocation for which no correctable cause could be identified, such as bony or soft-tissue insufficiency which was not amenable to repair or 


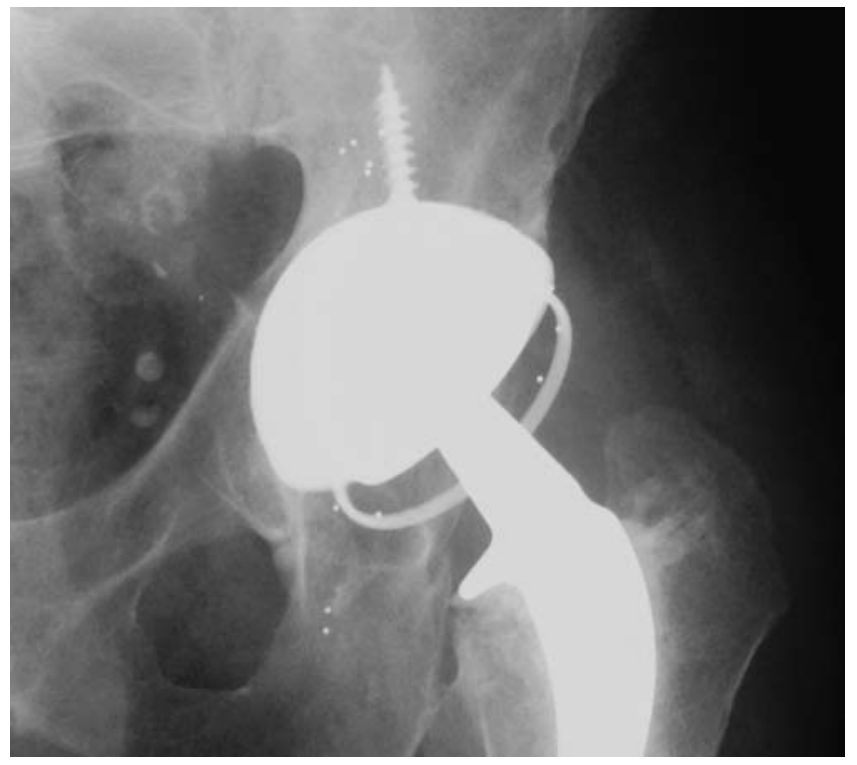

Fig. 1

Radiograph showing the constrained component with tantalum beads inserted for roentgen stereophotogrammetric analysis.

augmentation. We recruited 34 patients who were treated by a constrained acetabular component. There were 20 women and 14 men with a mean age of 73.1 years (46 to 91). The mean height and weight were $1.64 \mathrm{~m}$ (1.52 to $1.76)$ and $70.2 \mathrm{~kg}$ (47 to 125$)$, respectively. There were 21 procedures performed on the left hip and 13 on the right. The mean time between the primary THR and the initial revision procedure was 10.6 years ( 1 to 20 ). The mean number of dislocations was 4.1 ( 2 to 12 ).

The patients were reviewed clinically and radiologically by independent observers (SH, RA, RJKK). Post-operatively, they were seen at six weeks, three and six months, one year and annually for at least five years thereafter. They were scored pre-operatively using the Western Ontario and McMaster osteoarthritis index (WOMAC) score $^{31}$ and post-operatively by the WOMAC, the Harris hip ${ }^{32}$ and SF36 (physical component) ${ }^{33}$ scores. The last available radiographs of the patients who had died were reviewed.

Radiological assessment. Plain radiographs were taken to assess migration of the component, wear and loosening. The films were reviewed by two independent observers (RJKK, RA) and compared with previous films. The location of radiolucent lines was classified according to Gruen, McNeice and Amstutz ${ }^{34}$ and DeLee and Charnley. ${ }^{35}$ Loosening of uncemented femoral components was classified according to Engh, Bobyn and Glassman ${ }^{36}$ and of acetabular components using a modification of Engh's system, described by Bremner et al. ${ }^{26}$ Loosening of cemented components was classified according to Harris, McCarthy and $\mathrm{O}^{\prime} \mathrm{Neill}^{37}$ and Harris and McGann ${ }^{38}$ and heterotopic ossification according to Brooker et al. ${ }^{39}$ In addition, we mea-

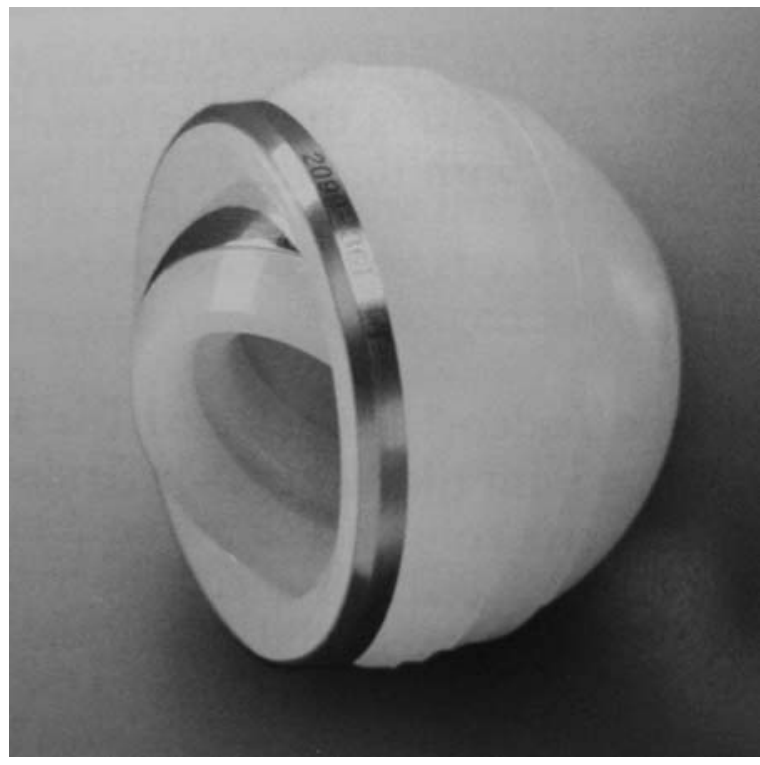

Fig. 2

Photograph of the Trident constrained component (tripolar articulation). sured component inclination, acetabular offset, femoral offset and the craniocaudal level of the joint, determined by the vertical height of the femoral head as a proportion of the distance between the transtuberosity line and a parallel line drawn bisecting the greater sciatic notch.

Tantalum beads were inserted into the acetabular component and pelvis at the time of the initial procedure (Fig. 1). Patients were followed up by post-operative (baseline), six-month and annual radiographs using the standard RSA technique. ${ }^{40}$ Migration and rotation of the component in three planes were recorded by two independent RSA technicians. Accuracy of the non-zero movement of the RSA technique was tested on pairs of radiographs taken on the same occasion but separated in time by five minutes. Any apparent migration on the radiographs was an error of non-zero movement.

Operative technique. All operations were performed or directly supervised by one of two surgeons (BN, DW) between 1999 and 2002, at the Sir Charles Gairdner Hospital or Hollywood Private Hospital, using a posterior approach in every case. The Trident constrained acetabular component (Stryker Orthopaedics, Mahwah, New Jersey) was used routinely (Fig. 2). At the completion of the operation the hips were put through a full range of movement to establish that there was no impingement. There were no restrictions to mobility, and patients were encouraged to walk from the first post-operative day. The mean length of hospital stay was 12.8 days (5 to 30 ).

Statistical analysis. This was performed by SPSS for Windows V12.0 (SPSS Inc., Chicago, Illinois). Paired data were analysed using the non-parametric Wilcoxon signed-rank 
Table I. Mean (SD) translation and rotation of the acetabular component. Calculations performed without direction. All movements are of the component in relation to the pelvis

\begin{tabular}{|c|c|c|c|c|}
\hline & \multirow[b]{2}{*}{ Axis } & \multicolumn{3}{|c|}{ Time interval after surgery (mths) } \\
\hline & & 6 & 12 & 24 \\
\hline \multirow[t]{3}{*}{ Translation (mm) } & Mediolateral & $0.76(0.96)$ & $0.88(0.98)$ & $0.77(0.87)$ \\
\hline & Proximodistal & $0.41(0.38)$ & $0.49(0.48)$ & $0.37(0.59)$ \\
\hline & Anteroposterior & $0.51(0.50)$ & $0.55(0.32)$ & $1.06(1.49)$ \\
\hline \multirow[t]{3}{*}{ Rotation ( ${ }^{\circ}$ ) } & Anteroposterior & $1.38(0.91)$ & $1.45(1.19)$ & $1.50(0.94)$ \\
\hline & Anteversion-retroversion & $1.83(1.66)$ & $1.51(1.43)$ & $1.57(1.61)$ \\
\hline & Varus-valgus & $1.23(1.28)$ & $1.70(1.28)$ & $2.32(2.07)$ \\
\hline
\end{tabular}

test and unpaired data by the Mann-Whitney U test. The chi-squared test and Fisher's exact test were used for categorical data as appropriate. The level of significance was set at $\mathrm{p}<0.05$.

\section{Results}

The mean clinical follow-up was 3.0 years (2.2 to 4.8$)$. Six patients died from unrelated illnesses. None was lost to follow-up. All surviving patients continue to be reviewed as outpatients. Four hips (four patients) were revised, leaving 24 patients followed up with the original constrained component in situ. The indications for revision were aseptic loosening in three hips and deep infection in one.

A total of 31 acetabular components were inserted by snap-fit into new, uncemented acetabular metal-backed shells. One component was cemented into a pelvic reconstruction cage. Two shells were well-fixed and in good position and thus were retained. Of these, one was compatible with the constrained liner and inserted by snap-fit, the other was not and the liner was cemented into the shell. In cases in which the acetabular component had been cemented into a metal cage or shell, the non-articulating side of the component was textured with a saw blade to aid interdigitation of cement.

There were 25 femoral components which were wellfixed and in a good position and therefore retained. Of the remainder, eight were revised with a cemented and one with an uncemented component. The mean number of screws used to secure the uncemented shells was two $(0$ to 4$)$. The median outer diameter of the inserted shells was $56 \mathrm{~mm}(50$ to 64$)$. The size of the femoral head was $22 \mathrm{~mm}$ for shells of $50 \mathrm{~mm}$ to $56 \mathrm{~mm}$ (22 hips) and $28 \mathrm{~mm}$ for shells of $58 \mathrm{~mm}$ to $64 \mathrm{~mm}$ (12 hips). Acetabular bone defects were reconstructed using morsellised allograft in 11 patients.

Functional evaluation. The mean WOMAC score in 34 patients improved significantly from 53.7 pre-operatively to 63.27 post-operatively $(\mathrm{p}=0.008)$. The mean SF-36 score (physical component) and the Harris Hip score at the most recent follow-up were 30.5 (14.3 to 54.1) and 69.0 (29 to 94), respectively.

The mean range of movement of the hip at follow-up was $88^{\circ}\left(65^{\circ}\right.$ to $\left.110^{\circ}\right)$ of flexion, $26^{\circ}\left(0^{\circ}\right.$ to $\left.50^{\circ}\right)$ of abduction, $22^{\circ}$ $\left(0^{\circ}\right.$ to $\left.40^{\circ}\right)$ of adduction, $20^{\circ}\left(0^{\circ}\right.$ to $\left.45^{\circ}\right)$ of external rotation and $18^{\circ}\left(0^{\circ}\right.$ to $\left.50^{\circ}\right)$ of internal rotation. There were no fixed
Table II. The mean error (at the $95 \%$ significance level) of non-zero movement of the acetabular component relative to the pelvis

\begin{tabular}{lll}
\hline & Axis & Mean error \\
\hline Translation $(\mathrm{mm})$ & Mediolateral & 0.17 \\
& Proximodistal & 0.13 \\
& Anteroposterior & 0.18 \\
Rotation $\left(^{\circ}\right)$ & Anteroposterior & 0.57 \\
& Anteversion-retroversion & 0.79 \\
& Varus-valgus & 0.70 \\
\hline
\end{tabular}

flexion deformities. There was no significant difference in the mean range of movement between those with a $22 \mathrm{~mm}$ head and those with a $28 \mathrm{~mm}$ head.

Of the 28 patients alive at follow-up, 25 resided in their own home and three lived in a residential or nursing home. Radiological evaluation. The mean length of radiological follow-up was 2.7 years (2.0 to 4.8). No femoral components were loose or had been revised. Radiolucent lines were found in four of the 24 patients with the original acetabular component still in situ, while none were identified at the final follow-up in the deceased patients. There were three stable acetabular components with non-circumferential radiolucent lines. Specifically, one had a lucency in DeLee and Charnley ${ }^{35}$ zone 1 , one in zone 2 and one in zone 3. One component was radiologically unstable with progressive radiolucent lines in all zones and was awaiting revision. Three acetabular components were revised because of aseptic loosening by the time of latest follow-up. The remainder were asymptomatic. The overall rate of aseptic loosening was, therefore, $11.8 \%$ (4 of 34).

The four components which were revised failed early and were not available for the RSA study, leaving 30 for analysis (including the last data collected on the deceased patients). The results of the RSA analysis to establish micromovement of the acetabular component in the first 24 months are given in Table I. Most migration occurred in the first six months. There was significantly more migration (translation and rotation) in the one unstable acetabular component awaiting revision than the remaining 29 components which were radiologically stable $(\mathrm{p}<0.001)$. There was no difference in the migration between the three stable components with non-circumferential radiolucent lines and 


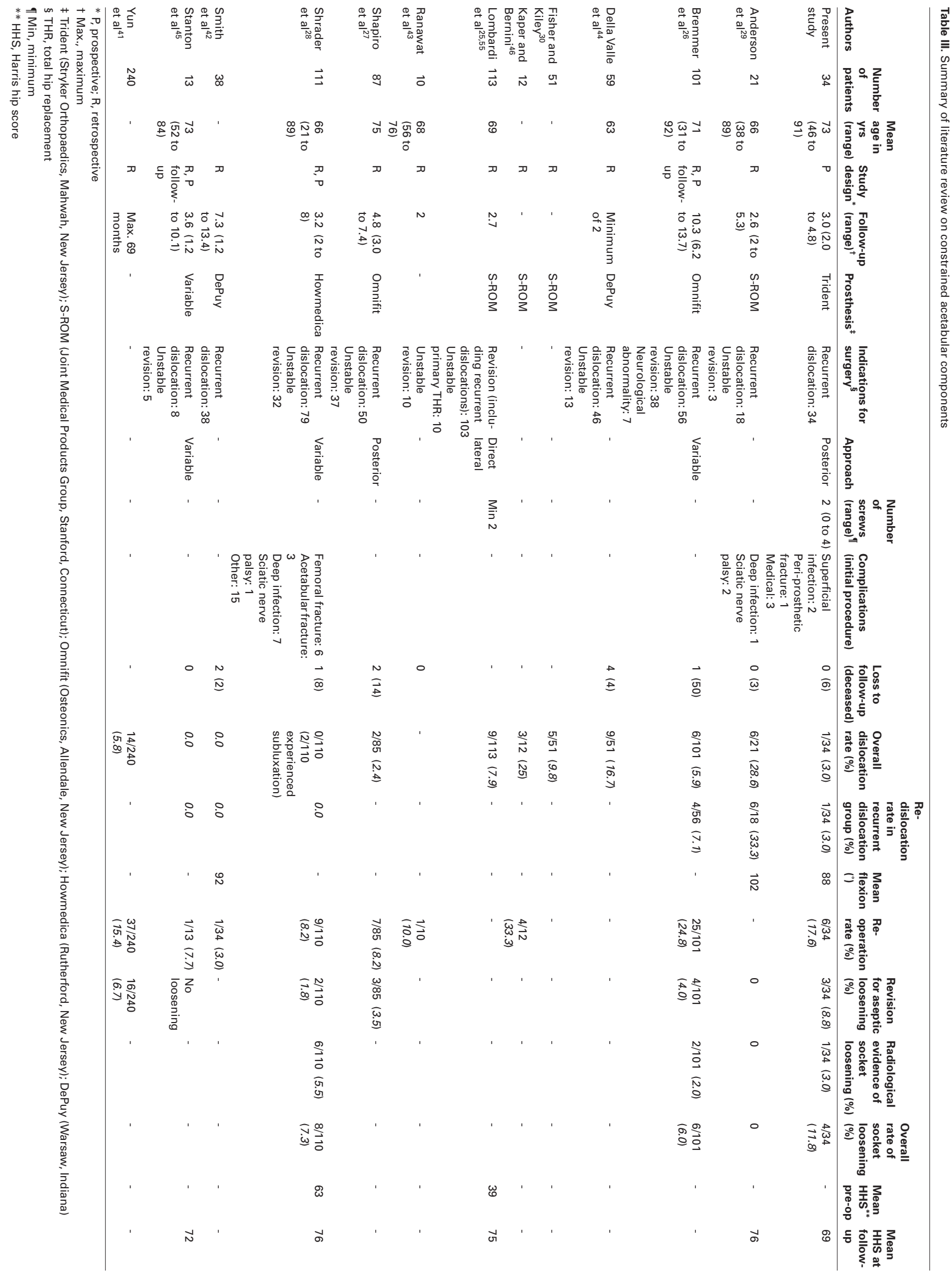


those with no radiolucent lines present. The mean error (at the $95 \%$ significance level) of non-zero movement of the component relative to the pelvis is given in Table II.

Complications. At the most recent follow-up only one patient had experienced a further dislocation. This patient also suffered a dissociation of the constrained liner from the acetabular shell. Both these events followed falls. This patient had already undergone a revision of the constrained acetabular component for aseptic loosening and went on to require three further revisions.

Early complications (during the in-patient stay) occurred in six of the 34 patients $(17.6 \%)$. These included a superficial wound infection in two, peri-prosthetic fracture in one and deep-vein thrombosis in one, a cardiac event in one and a cerebrovascular accident in one. The peri-prosthetic fracture was identified intra-operatively and treated by a plate, cables and strut allograft.

Late complications occurred in five of 34 patients $(14.7 \%)$. These included aseptic loosening of the acetabular component in three, deep infection in one, peri-prosthetic fracture in one and dislocation and subsequent dissociation also in this patient. The patient with deep infection was treated by two-stage revision. The overall re-operation rate after the initial procedure was eight operations in six patients.

Regression analysis found no significant association between migration or loosening of the component and age, gender, size of the component, the use of bone graft, or the position of the component in the vertical and horizontal planes. The inverse association between the number of screws used to secure the component and subsequent loosening almost reached statistical significance $(\mathrm{p}=0.09)$.

\section{Discussion}

Constrained acetabular liners are widely produced. Irrespective of whether they are of bipolar (single articulation) or tripolar (double articulation) design, they work by capturing the femoral head within the acetabular component by means of a locking mechanism. Different designs accept head sizes of varying diameter and have differing amounts of rim elevation and offset, allowing slight variations in the range of movement allowed. Once the limit to movement has been reached, impingement occurs. In the nonconstrained component further excursion of the head results in dislocation. However, in the constrained component, impingement occurs and transmits force to the linershell and shell-bone interfaces. In contrast, semi-constrained devices, such as the angle-bore component ${ }^{13}$ or the augmentation wedge, ${ }^{11}$ and large femoral heads increase stability by increasing the excursion before dislocation can occur.

We identified a number of studies in which constrained acetabular components had been used (Table III). All were retrospective. There were five which had been published as abstracts only, with minimal reporting of outcome..$^{25,41-44}$ There were four with small patient numbers, precluding meaningful interpretation of the results. ${ }^{29,30,45,46}$ There have been three large series published to date with a mean follow-up of 3.2 years, ${ }^{28} 4.8$ years ${ }^{27}$ and 10.3 years. ${ }^{47}$ Most studies have included a diverse case mix with unstable revisions as well as recurrent dislocators, making comparison of results difficult.

From our results and review of the literature there is evidence that the constrained liner is successful in providing stability in patients with recurrent dislocation. Our findings are supported by those of other large series. Shrader et al ${ }^{28}$ reported no further dislocations at 3.2 years and Callaghan et $\mathrm{al}^{47}$ had a dislocation rate of only $7.1 \%$ at ten years.

However, the success in achieving stability must be balanced by the evidence of early loosening of the component. Our finding of loosening of $11.8 \%$ at 2.7 years is higher than that reported in previous studies. Shrader et $\mathrm{al}^{28}$ reported that two $(1.8 \%)$ acetabular components were revised for aseptic loosening and a further six $(5.5 \%)$ had radiolucent lines in all zones. Callaghan et $\mathrm{a}^{47}$ reported a lower rate of loosening of $5.9 \%$ at a mean of ten years. Saleh et $\mathrm{al},{ }^{48}$ in a meta-analysis using a fixed-effects analysis of 39 studies involving 2578 patients with a mean followup of 57 months after revision hip replacement, using nonconstrained acetabular components found a mean acetabular loosening rate of $5.85 \%(1.136 \%$ to $23.80 \%)$. The only study with RSA data on the rate of migration of a cementless acetabular component reported up to $0.4 \mathrm{~mm}$ of migration at six months. ${ }^{49}$ Our results for loosening and migration are worse than those of these historical controls. However, comparisons of loosening rates between constrained cementless components and non-constrained cementless components should be made cautiously, since patient populations may not be similar. Also, the constrained acetabular component is often used as a salvage procedure when other options have failed.

At follow-up, the acetabular components were either stable with no or very few radiolucent lines and minimal migration (29 of $34,85.2 \%$ ) or they loosened early requiring re-revision. The discrepancy between the high rate of loosening (4 of $34,11.8 \%$ ) and the relatively low rates of migration of the component on RSA (up to $1.06 \mathrm{~mm}$ ) is explained by the exclusion of the four patients with revision for loosening on whom RSA was not performed. Only one of the 30 components for which RSA data were available was unstable, thus skewing the data towards lower overall migration. Although there was a trend for increased rates of loosening with components inserted with no screws or a single screw, regression analysis identified no other risk factors. The migration distances at 24 months fell just within the $1 \mathrm{~mm}$ to $2 \mathrm{~mm}$ limits quoted as being predictive of early failure. ${ }^{50}$ Therefore, careful long term follow-up of this group is required.

Other potential drawbacks to the constrained liner include a reduced range of movement and dislocation or dissociation requiring open reduction. Closed reduction was not attempted in our series, although there have been reports of occasional success in the literature. ${ }^{51,52} \mathrm{~A}$ 
reduced range of movement of the hip with the constrained component did not appear to be a problem in our series with a mean hip flexion of $88^{\circ}$. This degree of flexion, although less than that reported by other studies, ${ }^{29,42}$ is slightly greater than that provided by the component itself, ${ }^{53,54}$ indicating that some movement was occurring as the pelvis rotated.

Although our follow-up is relatively short, given the finding of early loosening of the component we feel justified in presenting our preliminary results. To our knowledge, this study is the first to use RSA to measure migration of constrained acetabular components accurately. Since collection of the data has been prospective, our findings are accurate and more comprehensive than those of previous studies.

Our results confirm that the constrained acetabular component is an effective option for the treatment of patients with instability of the hip. However, the high rate of aseptic loosening is of concern and requires further investigation.

No benefits in any form have been received or will be received from a commercial party related directly or indirectly to the subject of this article.

\section{References}

1. Woo RY, Morrey BF. Dislocations after total hip arthroplasty. J Bone Joint Surg [Am] 1982;64-A:1295-306.

2. Turner RS. Postoperative total hip prosthetic femoral head dislocations: incidence, etiologic factors, and management. Clin Orthop 1994;301:196-204.

3. Paterno SA, Lachiewicz PF, Kelley SS. The influence of patient-related factors and the position of the acetabular component on the rate of dislocation after total hip replacement. J Bone Joint Surg [Am] 1997;79-A:1202-10

4. Williams JF, Gottesman MJ, Mallory TH. Dislocation after total hip arthroplasty: treatment with an above-knee hip spica cast. Clin Orthop 1982;171:53-8.

5. Haidukewych GJ, Boberg CJ, Morrey BF. The financial impact of dislocation as a complication of primary total hip arthroplasty. Procs AAOS Annual Meeting 2004;5: 407-8.

6. Morrey BF. Hip dislocation: it's later than you think. Orthopedics 2000;23:935-6.

7. Alberton GM, High WA, Morrey BF. Dislocation after revision total hip arthroplasty: an analysis of risk factors and treatment options. J Bone Joint Surg [Am]2002; 84-A:1788-92.

8. Dorr LD, Wolf AW, Chandler R, Conaty JP. Classification and treatment of dislocations of total hip arthroplasty. Clin Orthop 1983;173:151-8.

9. Daly PJ, Morrey BF. Operative correction of an unstable total hip arthroplasty. J Bone Joint Surg [Am] 1992;74-A:1334-43.

10. Kavanagh BF, Fitzgerald RH Jr. Multiple revisions for failed total hip arthroplasty not associated with infection. J Bone Joint Surg [Am] 1987;69-A:1144-9.

11. Olerud S, Karlstrom G. Recurrent dislocation after total hip replacement: treatment by fixing an additional sector to the acetabular component. J Bone Joint Surg [Br] 1985;67-B:402-5.

12. Charlwood AP, Thompson NW, Thompson NS, Beverland DE, Nixon JR. Recurrent hip arthroplasty dislocation: good outcome after cup augmentation in 20 patients followed for 2 years. Acta Orthop Scand 2002;73:502-5.

13. Porter $\mathbf{P}$, Stone $\mathbf{M H}$. Total hip arthroplasty using the Wroblewski golf ball cup inserted through the posterior approach: a high rate of dislocation. J Bone Joint Surg [Br] 2004;86-B:643-7.

14. Kelley SS, Lachiewicz PF, Hickman JM, Paterno SM. Relationship of femoral head and acetabular size to the prevalence of dislocation. Clin Orthop 1998;355:163-70.

15. Beaule PE, Schmalzried TP, Udomkiat P, Amstutz HC. Jumbo femoral head for the treatment of recurrent dislocation following total hip replacement. J Bone Joint Surg [Am] 2002;84-A:256-63.

16. Bystrom S, Espehaug B, Furnes 0, Havelin LI, Norwegian Arthroplasty Register. Femoral head size is at risk factor for total hip luxation: a study of 42,987 primary hip arthroplasties from the Norwegian Arthroplasty Register. Acta Orthop Scand 2003;74:514-24

17. Parvizi J, Morrey BF. Bipolar hip arthroplasty as a salvage treatment for instability of the hip. J Bone Joint Surg [Am] 2000;82-A:1132-9.

18. Berry DJ. Unstable total hip arthroplasty: detailed overview. Instr Course Lect 2001; 50:265-74.
19. Kaplan SJ, Thomas WH, Poss R. Trochanteric advancement for recurrent dislocation after total hip arthroplasty. J Arthroplasty 1987;2:119-24.

20. Stromsoe K, Eikvar K. Fascia lata plasty in recurrent posterior dislocation after total hip arthroplasty. Arch Orthop Trauma Surg 1995;114:292-4.

21. Mahoney CR, Pellicci PM. Complications in primary total hip arthroplasty: avoidance and management of dislocations. Instr Course Lect 2003;52:247-55.

22. Fujishiro T, Nishikawa T, Takikawa S, et al. Reconstruction of the iliofemoral ligament with an artificial ligament for recurrent anterior dislocation of total hip arthroplasty. J Arthroplasty 2003;18:524-7

23. Su EP, Pellicci PM. The role of constrained liners in total hip arthroplasty. Clin Orthop 2004;420:122-9.

24. Sivash KM. The development of a total metal prosthesis for the hip joint from a partial joint replacement. Reconstr Surg Traumatol 1969;11:53-62.

25. Lombardi AV Jr, Mallory TH, Kraus TJ, Vaughn BK. Preliminary report on the SROM constraining acetabular insert: a retrospective clinical experience. Orthopedics 1991;14:297-303.

26. Bremner BR, Goetz DD, Callaghan JJ, Capello WN, Johnston RC. Use of constrained acetabular components for hip instability: an average 10-year follow-up study. J Arthroplasty 2003;18:131-7.

27. Shapiro GS, Weiland DE, Markel DC, et al. The use of a constrained acetabular component for recurrent dislocation. J Arthroplasty 2003;18:250-8.

28. Shrader MW, Parvizi J, Lewallen DG. The use of a constrained acetabular component to treat instability after total hip arthroplasty. J Bone Joint Surg [Am] 2003; 85-A:2179-83.

29. Anderson MJ, Murray WR, Skinner HB. Constrained acetabular components J Arthroplasty 1994;9:17-23.

30. Fisher DA, Kiley K. Constrained acetabular cup disassembly. J Arthroplasty 1994;9 325-9

31. Bellamy N, Buchanan WW, Goldsmith CH, Campbell J, Stitt LW. Validation study of WOMAC: a health status instrument for measuring clinically important patient relevant outcomes to antirheumatic drug therapy in patients with osteoarthritis of the hip or knee. J Rheumatol 1988;15:1833-40.

32. Harris HW. Traumatic arthritis of the hip after dislocation and acetabular fractures treatment by mold arthroplasty: an end-result stage using a new method of result evaluation. J Bone Joint Surg [Am] 1969;51-A:737-55.

33. Ware JE, Sherbourne CD. The MOS 36-item short-form health survey (SF-36) I Conceptual framework and item selection. Med Care 1992;30:473-83.

34. Gruen TA, McNeice GM, Amstutz HC. "Modes of failure" of cemented stem-type femoral components: a radiographic analysis of loosening. Clin Orthop 1979;141:17-27.

35. DeLee JG, Charnley J. Radiological demarcation of cemented sockets in total hip replacement. Clin Orthop 1976;121:20-32.

36. Engh CA, Bobyn JD, Glassman AH. Porous-coated hip replacement: the factors governing bone ingrowth, stress shielding, and clinical results. J Bone Joint Surg [Br] 1987;69-B:45-55.

37. Harris WH, McCarthy JC Jr, O'Neill DA. Femoral component loosening using contemporary techniques of femoral cement fixation. J Bone Joint Surg [Am] 1982;64-A 1063-7

38. Harris WH, McGann WA. Loosening of the femoral component after use of the medullary-plug cementing technique: follow-up note with a minimum five-year follow-up. J Bone Joint Surg [Am] 1986;68-A:1064-6.

39. Brooker AF, Bowerman JW, Robinson RA, Riley LH Jr. Ectopic ossification following total hip replacement: incidence and a method of classification. J Bone Joint Surg $[A m]$ 1973;55-A:1629-32.

40. Selvig G. Roentgen stereophotogrammetry: a method for the study of the kinematics of the skeletal system. Acta Orthop Scand 1989;60:Suppl 232

41. Yun A, Padgett DE, Pellici PM. Constrained acetabular liners: mechanism of failure. Procs AAOS Annual Meeting 2004;5:400

42. Smith R, Saint Paul MN, Bert JM. Use of constrained polyethylene acetabular component liners in revision THA: long term follow up in 38 cases. Procs AAOS Annual Meeting 2004;5:416.

43. Ranawat CS, DiGiovanni C, Pellici P. Treatmnt of recurrent instability after hybrid total hip arthroplasty by cementing constrained, all-polyethylene liners into wellfixed, metal backed shells: two-year results. Procs AAOS Annual Meeting 2000.

44. Della Valle C, Chang DH, Sporer SM, Paprowsky WG. High failure rate of a constrained acetabular liner in revision total hip arthroplasty. Procs AAOS Annual Meeting 2004;5:384.

45. Stanton DA, Bruce WJ, Goldberg JA, Walsh W. Salvaging unstable or recurrent dislocating total hip arthroplasty with the constrained acetabular component J Orthop Surg (Hong Kong) 2002;10:165-9.

46. Kaper BP, Bernini PM. Failure of a constrained acetabular prosthesis of a total hip arthroplasty: a report of four cases. J Bone Joint Surg [Am] 1998;80-A:561-5.

47. Callaghan JJ, O'Rourke MR, Goetz DD, et al. Use of a constrained tripolar acetabular liner to treat intraoperative instability and postoperative dislocation after total hip arthroplasty: a review of our experience. Clin Orthop 2004;429:117-23. 
48. Saleh KJ, Celebrezze M, Kassim R, et al. Functional outcome after revision hip arthroplasty: a metaanalysis. Clin Orthop 2003;416:254-64.

49. Nivbrant B, Karrholm J, Onsten I, Carlsson A, Snorrason F. Migration of porous press-fits cups in hip revision arthroplasty: a radiostereometric 2-year follow-up study of 60 hips. J Arthroplasty 1996;11:390-6.

50. Karrholm J, Herberts P, Hultmark P, et al. Radiostereometry of hip prostheses: review of methodology and clinical results. Clin Orthop 1997;344:94-110.

51. Harman MK, Hodge WA, Banks SA. Closed reduction of constrained total hip arthroplasty. Clin Orthop 2003;414:121-8.
52. Miller CW, Zura RD. Closed reduction of a dislocation of a constrained acetabular component. J Arthroplasty 2001;16:504-5.

53. Su EP, Shapiro GS, Pellicci PM. The use of constrained acetabular sockets. Techniques in Orthopaedics 2001;16:237-44.

54. Lachiewicz PF, Kelley SS. The use of constrained components in total hip arthroplasty. J Am Acad Orthop Surg 2002;10:233-8.

55. Lombardi AV Jr, Mallory TH, Fada R, et al. Early results of acetabular reconstruction using an acetabular component with constrained liner. Procs AAOS Annual Meeting 2000 